Original Article

\title{
Pathophysiological Correlation between Diabetes Mellitus Type-II and Chronic Obstructive Pulmonary Diseases
}

\author{
Ahmad N. Bitar, Muhammad Ali Ghoto, Abdullah Dayo, Mudassar Iqbal Arain, \\ Rabia Parveen
}

ABSTRACT

INTRODUCTION: Diabetes Mellitus, a chronic disease is usually associated and linked to many other conditions and complications. Chronic Obstructive Pulmonary Disease (COPD); a life threatening progressive inflammatory lung disease associated with chronic bronchitis and emphysema; when associated with Diabetes Mellitus generates a huge burden on patients quality of life as well as on health care systems.

OBJECTIVE: Although link between DM and COPD is not scientifically established or confirmed yet, however evidence suggest a pathophysiological correlation between both conditions might be present. This study focuses upon impact of DM on the onset of COPD and to find if there is any evidence of the suggested pathophysiological correlation.

METHODOLOGY: We retrospectively analyzed 120 cases of Chronic Obstructive Pulmonary Disease (COPD), data collected from General Medical Units and Pulmonary Ward of Liaquat University Teaching Hospital, Jamshoro / Hyderabad from January till June, 2016.

RESULTS: The majority of cases with COPD were male representing $81.6 \%$ of the sample population, almost $90 \%$ of patients were smokers or ex-smokers, $42.50 \%$ of COPD patients were suffering from DM and $\mathbf{7 6 . 4 7 \%}$ were either non-compliant or had a very poor control over their blood glucose level. Blood glucose levels of most of the patients was from $140 \mathrm{mg} / \mathrm{dl}$ to $500 \mathrm{mg} / \mathrm{dl}$ and $19.60 \%$ of patients reached diabetic ketoacidosis (DKA) once at least.

CONCLUSION: DM increases the risk for occurrence of COPD and cause rapid decline in clinical state of the patient. Unlike cardiovascular complication of diabetes in case of diabetic patients with COPD the lower the BMI the higher the risk of mortality.

KEYWORDS: Diabetes Miletus (DM), Chronic Obstructive Pulmonary Diseases (COPD), Pathophysiological Correlation.

This article may be cited as: Bitar AN, Ghoto MA, Dayo A, Arain MI, Parveen R. Pathophysiological Correlation between Diabetes Mellitus Type-II \& Chronic Obstructive Pulmonary Diseases. J Liaquat Uni Med Health Sci. 2017;16(01):41-8. doi: 10.22442/jlumhs.171610504

\section{INTRODUCTION}

Diabetes Mellitus (DM) is a chronic disease that is associated with multiple disorders and a major risk for many other complications. In a nutshell DM can be described as the "Mother of Diseases" which is responsible for millions of deaths and a huge financial burden of hundreds of billions of US dollars every year for management and treatment of the complications associated with this disease. Type-I DM is featured by complete absence or deficiency of insulin which occurs due to an autoimmune or idiopathic cause in $90 \%$ of cases leading to complete destruction of beta cells in the pancreas. Patients who suffer from Type-I DM cannot survive without insulin injections. While Type-II DM commonly represented with insulin resistance that can lead to cell dysfunction causing elevation of blood glucose level in blood stream due to metabolism malfunction ${ }^{1}$.

Chronic Obstructive Pulmonary Disease (COPD) is a life threatening progressive inflammatory lung disease associated with chronic bronchitis and emphysema. COPD carries high morbidity rate; according to the British Lung Foundation (BLF), it affects almost 3 million patients in the $\mathrm{UK}^{2}$ and almost 329 million all around the world ${ }^{3-4}$. In case of emphysema the air sacs are damaged, while in bronchitis air ways is inflamed and sometimes both conditions may coexist ${ }^{2}$. COPD symptom includes wheezing especially during exhaling, active as well as resting breathlessness, chest tightness, and productive cough. These symptoms worsen because of chest infections, 
inhaling fumes, and smoking. Sometimes patients present with complains of appetite loss, loss of weight, and swelling of ankles ${ }^{4}$.

Large number of elderly population may suffer from many chronic diseases simultaneously. More than $25 \%$ of patients over 65 years old suffer from more than one chronic disease and this figure goes up to $40 \%$ in patients over 75 years of age ${ }^{5}$. Prevalence of COPD is higher among older patients and in populations that consumes tobacco products as it is estimated that $4-10 \%$ of smokers suffer from COPD worldwide $^{6}$ and $\mathrm{WHO}$ has identified COPD as the fourth leading cause of death in hospitals ${ }^{7}$.

It suggested that the prolonged use of corticosteroids for the management of COPD might be linked to the high blood glucose level in these patients. Others claim that even though steroids drugs can mildly increase blood glucose level, the effect of these drugs in its inhaled form on blood glucose levels is negligible. This study concentrate on the impact of DM upon the onset of COPD, and aims to identify whether there is a significant evidence of possible pathophysiological correlations between Diabetes Mellitus (DM) and Chronic Obstructive Pulmonary Disease (COPD).

\section{Hypothetical explanation of the possible Correla- tion between DM and COPD:}

The link between DM and cardiovascular diseases is already established and extensively studied and the microvascular as well as the macrovascular complications of DM are also scientifically established notion, at the same time it is also well known that blood supply is essential for all vital organs and any

\section{FIGURE I:}

\section{THE CORRELATION BETWEEN DM AND COPD}

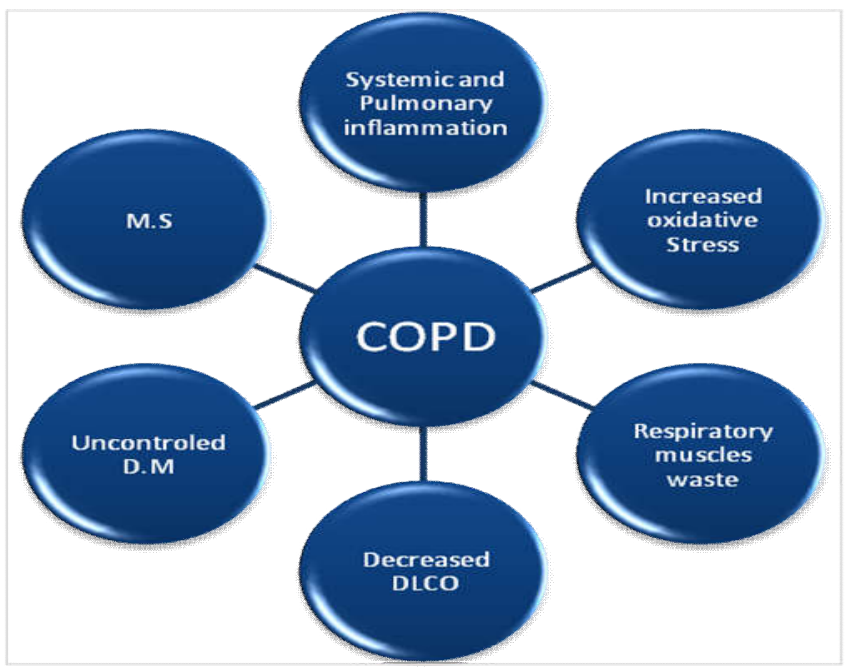

disturbance in blood supply or contents leads to serious complications. In fact the recent studies have shown that an uncontrolled hyperglycemia can leads to prolonged hospitalization, increases the prevalence of bacterial infections, and sometimes cause pulmonary hypertension which might lead to death ${ }^{14-}$ 17. The frequency of association DM with COPD and relation between both diseases is not clearly established, however some studies and reports suggests that $2-37 \%$ of COPD suffers from DM.

The pathophysiological correlation between DM and COPD is very complex and can be explained from different perspectives. First, it is well known that persistent hyperglycemia leads to formation of ketone bodies which on long term causes multi-organs functional disturbance, oxidative stress and leads to respiratory ketoacidosis due to the decrease in diaphragmatic movement because of fatigue and hyper-inflation due to increased acidity of the blood. Repeated and frequent occurrence of this phenomenon can lead to inflammatory response and destroy alveolus gases exchange membrane and capillaries barriers decreasing lung diffusing capacity in patient with $\mathrm{DM}^{17}$.

Secondly, Poor glycemic control can be associated with metabolic disturbance of carbohydrates, lipids and protein which contribute in metabolic syndrome (MS); few recent studies suggested a pathophysiological correlation or linked between MS and COPD ${ }^{17-18}$. Thirdly, diabetes mellitus is well known to cause systemic inflammatory response which increases inflammatory mediators in blood stream which leads to respiratory exacerbation in case of COPD. Added to that the parenchymal non-enzymatic glycosylation that may occur due hyperglycemia leads to increase in the thickness of basal lamina which increase the risk of respiratory infections, smooth muscles weakness and muscles wasting ${ }^{18-19}$.

DM and COPD have multiple features in common in term of their prognosis, pathogenesis and progress; for instance hypoxic effect, development of insulin resistance, high oxidative stress and inflammatory complications. The induced hyperglycemia during experimentations on mice showed a sudden increase in inflammatory mediators like interleukin-6 (IL-6) which may cause vascular and pulmonary damage significant increase in C-Reactive Protein (CRP) in people with insulin resistance because of over production of Reactive Oxygen Species (ROS), and tumor necrotic 
factor (TNFa) which suggest involvement of oxidative mechanisms that leads to production of cytokines ${ }^{21-24}$. Lung diffusing capacity of carbon monoxide (DLCO) in patient with DM have shown to be decreased along with low respiratory muscles strength, according to multiple studies in Japan and the US which have revealed that diabetic patients have lower FVC levels in general even those who do not suffer from pulmonary diseases and complications ${ }^{29-30}$, in fact diabetic patients with poor glycemic control were suffering from restriction in lung expanding volume as well. The results of third National Health and Nutrition Examination Survey of United Kingdom showed that patients with glucose level higher than $75 \mathrm{~g}$ in glucose tolerance test showed less endurance to physical activity and lower FEV1/FVC in general ${ }^{31-32}$. It has recently been shown that hyperglycemia cause deterioration in clinical condition of patients with COPD, and respiratory function of these type-II diabetic patients can be improved if diabetes is controlled using insulin sensitizers ${ }^{28-35}$. And that opens the door for investigating other classes of medications that can be helpful to control inflammatory and immune responses like Phospho-Diesterase4 (PDE4) selective inhibiters to reduce chronic inflammation of respiratory diseases like COPD, by blocking PDE4 the amount of CAMP metabolism will be decreased and that will prevent the release of inflammatory signaling mediators like Cytokine which will reduce the amount Reactive Oxygen species (ROS) produced ${ }^{40}$.

\section{METHODOLOGY}

After approval from the Ethical committee of the institute, study sample consisted of 120 diagnosed cases of Chronic Obstructive Pulmonary Disease was collected from General Medical Units (60 cases) and Pulmonary Ward (60 cases) of Liaquat University Teaching Hospital, Jamshoro / Hyderabad. All hospitalized patients aged between 40-90 years were considered, however sample achieved using disproportionate stratified random sampling technique during period of study between Jan 2016 to June-2016. The selected patients were grouped as per severity of COPD using Global Initiative for Obstructive Lung Disease (GOLD), and stratified according to the age using 10 years as a dividing interval. Non-hospitalized patients, children and patients under 40 or above 90 years of age were not considered for this study.
The data collected, on especially designed proforma, includes demographic information, clinical investigation and results of spirometry including FEV1.

\section{RESULTS}

\section{Demographic Distribution of the sample}

Distribution based on area of residence showed that vast majority of patients with COPD were from urban areas (like Hyderabad city, Nawabshah, Moro..) representing $69.17 \%(n=83)$, while $30.83 \%$ were from rural areas.

\section{FIGURE II:}

AREA BASED DISTRIBUTION OF THE SAMPLE

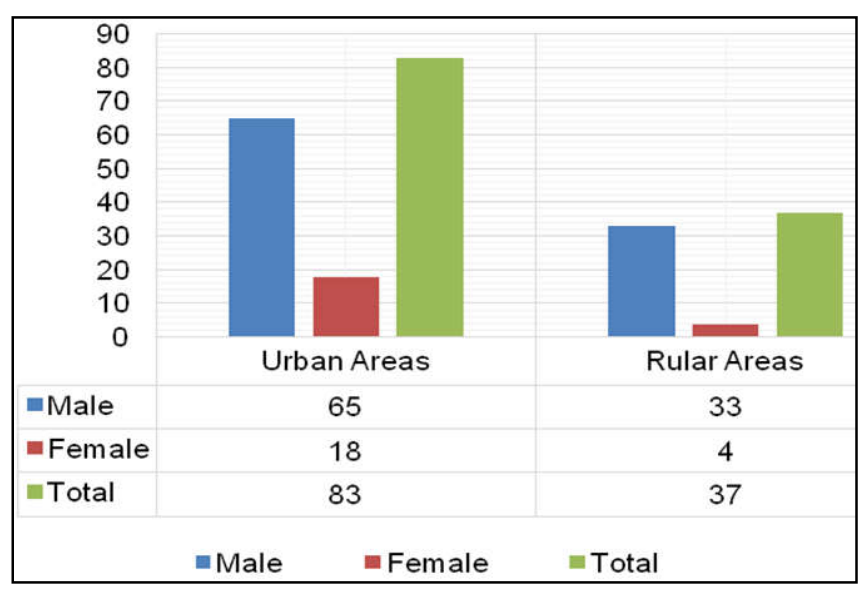

\section{Gender and size wise distribution and analysis}

Cases were collected from various cubes and rooms of pulmonary ward $(50 \%)$ and from the various general medicine wards and units $(50 \%)$. Gender distribution showed that number of male patients with COPD was more than four times higher than females representing $81.6 \%$ ( $n=98)$ of cases, while female patients accounted for $19.4 \% \quad(n=22)$, except one female patients admitted in medical ward, all female were from pulmonary ward.

FIGURE III: DISTRIBUTION OF COLLECTED SAMPLES

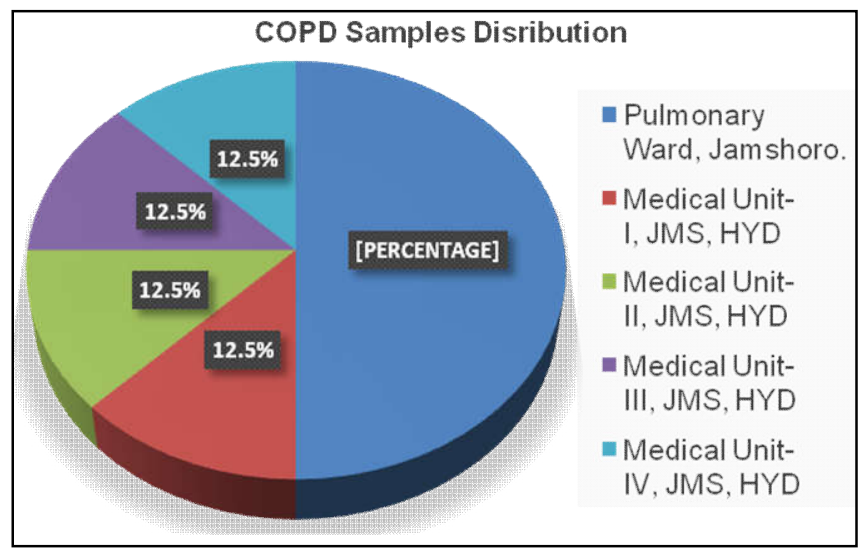




\section{The Correlation between COPD and other Compli- cations}

The DM was the most frequent comorbidity found associated with COPD as shown in graph 4 . Diabetic patients represented $58.33 \% \quad(n=35)$ of the cases collected from general medical units, $26.66 \%(n=16)$ of cases collected from pulmonary ward and $42.50 \%$ $(n=51)$ of all cases requited in the study. All other comorbidities like hypertension, liver diseases, hyperthyroidism, and lung carcinoma together represented the remaining $57.50 \% \quad(n=69)$. It is found that all COPD cases from general medicine units were complicated with other diseases, while in pulmonary ward COPD patients with other complication represented $55 \% \quad(n=33)$ and the remaining $45 \%$ $(n=27)$ of cases were diagnosed with COPD alone. Overall DM appeared to be the most prevalent comorbidity in both departments which strongly suggest that there is a correlation between these two.

\section{FIGURE IV: ANALYSIS OF THE CORRELATION BETWEEN COPD AND OTHER COMORBIDITIES}

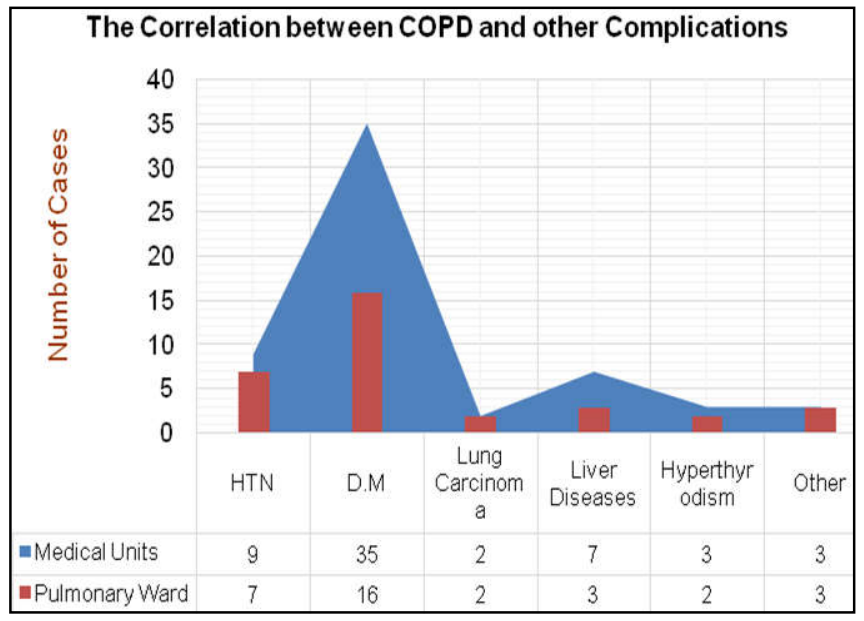

TABLE I: DISTRIBUTION OF PATIENTS ON THE BASES OF SEVERITY

\begin{tabular}{|l|c|c|c|c|}
\hline & $\begin{array}{c}\text { Stage-I } \\
\text { (Mild } \\
\text { COPD) }\end{array}$ & $\begin{array}{c}\text { Stage-II } \\
\text { (Moderate) }\end{array}$ & $\begin{array}{c}\text { Stage-III } \\
\text { (Severe) }\end{array}$ & $\begin{array}{c}\text { Stage-I } \\
\text { (Very } \\
\text { Severe) }\end{array}$ \\
\hline $40-50$ years & 21 & 13 & 5 & 2 \\
\hline $51-60$ years & 13 & 8 & 3 & 1 \\
\hline $61-70$ years & 5 & 7 & 2 & 3 \\
\hline $71-80$ years & 6 & 5 & 4 & 3 \\
\hline $81-90$ years & 4 & 6 & 5 & 4 \\
\hline
\end{tabular}

Distribution of Patients on the Bases of Severity

The cases were classified and grouped on the bases of severity using the Global Initiative for Obstructive Lung Disease (GOLD) criteria. It is clear that most of cases clustered in first two categories of mild and moderate COPD which combined represented $73.33 \%$ $(n=88)$ [Stage-I 40.83\% $(n=49)$ and Stage-II 32.50\% $(n=39)]$ of all cases, patients with severe COPD represented $15.83 \%(n=19)$ of the collected sample, while $10.83 \% \quad(n=13)$ of all patients were suffering from very severe COPD.

\section{Glycemic Control of DM patients}

The frequency of diabetic patients was 51 which is accounted for $42.5 \%$ of COPD patients, and $90.19 \%$ $(n=46)$ of them were with type-II D.M. More than three quarter of diabetic patients $(76.47 \%, n=39)$ were either non-compliant, or had a very poor control over their blood glucose levels. While in 16 cases $(31.37 \%)$ it was first time that DM was diagnosed.

Majority of the patients had high fasting blood sugar levels from $140 \mathrm{mg} / \mathrm{dl}$ to $500 \mathrm{mg} / \mathrm{dl}, 47.05 \%$ ( $=24)$ of them used to suffer frequently from high glucose levels in blood stream [more than $198 \mathrm{mg} / \mathrm{dl}(11 \mathrm{mmol} /$ L)], and $19.60 \%$ of the diabetic patients suffered from diabetic ketoacidosis (DKA) more than once. Also it has been noticed that patients with poor glycemic control were suffering from exaggerated inflammatory response in general and elevated amount of pro-inflammatory mediators in blood stream along with poor respiratory health condition.

TABLE II: NUMBER OF DIABETIC PATIENTS AND THEIR AVERAGE FASTING BLOOD GLUCOSE LEVELS IN MG/DL

\begin{tabular}{|l|c|c|c|c|c|}
\hline & $\begin{array}{c}\mathbf{8 0 - 1 4 0} \\
\mathbf{m g} / \mathbf{d l} .\end{array}$ & $\begin{array}{c}\mathbf{1 4 1 - 2 0 0} \\
\mathbf{m g} / \mathbf{d l} .\end{array}$ & $\begin{array}{c}\mathbf{2 0 1 - 2 6 0} \\
\mathbf{m g} / \mathbf{d l} .\end{array}$ & $\begin{array}{c}\mathbf{2 6 1 - 3 2 0} \\
\mathbf{m g} / \mathbf{d l} .\end{array}$ & $\begin{array}{c}\mathbf{3 2 1} \mathbf{~ m g} / \\
\mathbf{d l} \text { and } \\
\text { above }\end{array}$ \\
\hline 40-50 years & 3 & 6 & 5 & 4 & 1 \\
\hline $51-60$ years & 2 & 2 & 3 & - & 1 \\
\hline $61-70$ years & 4 & 4 & 3 & 2 & - \\
\hline $71-80$ years & 2 & 3 & 2 & 2 & 1 \\
\hline $81-90$ years & 1 & - & - & - & - \\
\hline
\end{tabular}

\section{COPD and Airways Obstruction}

The causes of airways obstruction in patients with COPD varied from infections, bronchitis, emphysema, effusion or even asthma. It has been detected that in $66.66 \%(n=80)$ airways obstruction was caused due to inflammatory response which in the first place was ignited in $45 \% \quad(n=54)$ of patients by infectious diseases like Tuberculosis (T.B), Community Acquired Pneumonia (CAP), or some other respiratory infections. It is well known that hyperglycemia can promote and facilitate infectious diseases in general and specifically here repeated respiratory infections and diabetic patients are more susceptible for respiratory infections than other populations which play a major 
role in COPD development, prognosis, and exacerbations.

The total number of detected deaths was 16 , representing $13 \%$ of the studied sample, half of deaths occurred in general medicine wards and the other half were in pulmonary ward. Out of the total number of deaths $56.25 \%(n=9)$ were diabetic and almost all of them had a history of uncontrolled DM type-II, low $\mathrm{BMI}$, and frequent chest infections.

\section{FIGURE V: ANALYSIS OF AIRWAYS OBSTRUC- TION CAUSES IN PATIENTS WITH COPD}

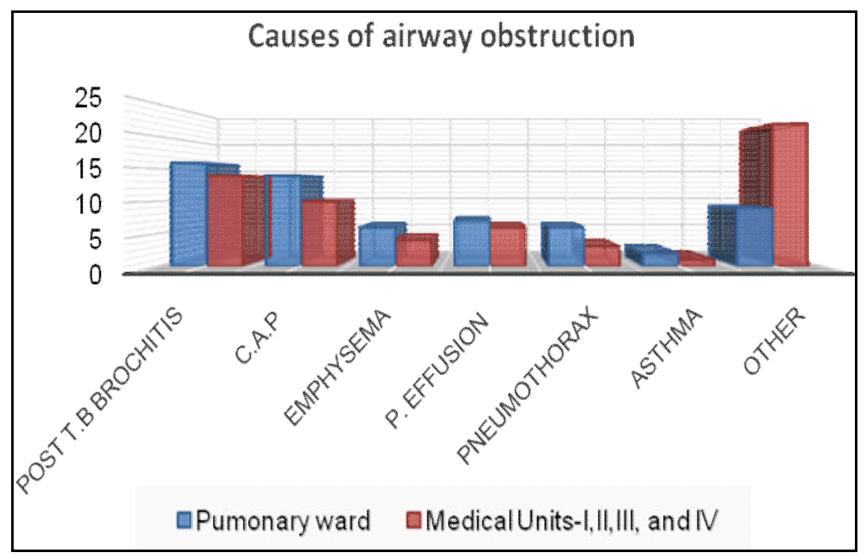

Weight and Body Mass Index Analysis

Despite the fact that a high number of diabetic patients were type-II, strangely most of them were not obese or overweight, but in fact most of them were underweight or severely underweight with BMI below $18 \mathrm{~kg} / \mathrm{m}^{2}$, which opens the door for questions wondering about the role of diabetes and COPD causing muscle wasting, respiratory function decline, and loss of weight which was encountered in almost $40 \%$ of patients with both conditions. These results can be linked to the difficulties in breathing which is associated with low ability to take food orally, the poor quality of life of these patients, and loss of appetite along with sleep apnea. In general the BMls of the majority of patients with both conditions (DM and COPD) were lower than $18 \mathrm{~kg} / \mathrm{m}^{2}$ especially in case of Stage III severe COPD (FEV1 30-49\% normal) and Stage IVvery severe COPD (FEV1 $<30 \%$ normal, or $<50 \%$ normal with chronic respiratory failure present).

\section{DISCUSSION}

The high prevalence of COPD in male as compared to female is due to multiple risk factors for example tobacco smoking which is much more common in males as compared to female population and almost $90 \%$ of cases were smokers or ex-smokers. Occupational factors also plays a contributing role, males are much more likely to be exposed to toxic fumes and dust due to employment in industrial areas.

After laboratory investigation it has been noticed that DM was the most frequent among all comorbidities associated with COPD representing $42.50 \%(n=51)$ of all cases which is higher than the number of patients with both conditions detected at the Italian College of General Practitioners which was fluctuating around $30 \%$ of patients ${ }^{18}$. This can indicate a pathophysiological correlations between both diseases, which can be linked to severe persistent hyperglycemia associated with poor glycemic control, elevated inflammatory mediators along with exaggerated inflammatory response in the blood stream, increased oxidative stress, and disturbed glucose metabolism ${ }^{22-39}$.

It is well known that diabetic patients are more susceptible to infectious diseases especially pulmonary infections like T.B, community acquired pneumonia, and Upper/lower respiratory tract infections ${ }^{14}$, which worsen the patient's condition and in more than $45 \%$ of the cases were responsible for the development of COPD. In fact high glucose level in blood stream is associated with high glucose level in lung tissues and it is linked to chest infections due to increased bacterial growth which leads to community acquired pneumonia (CAP) and COPD exacerbation ${ }^{25,26,34-36}$. It has been found that diabetic patients have 5-6 times higher risks to acquire lower respiratory tract infections, TB, and viral infections than non-diabetic individuals ${ }^{37-38}$.

Cross-sectional studies indicates that inflammatory response in systemic circulation did not occur in all patients with COPD but it occurred in most of COPD patients with diabetic ${ }^{22-39}$. High glucose level can also modulate bronchial tone and airways smooth muscles cells (ASM) directly by disturbing airways muscles cells molecular pathways through activating Rho/ ROCK pathways ${ }^{27}$, added to that the diabetic neuropathy that can be associated with malfunction of respiratory system due to its effect on respiratory muscles.

The BMI of most of patients with diabetes and COPD was less than $18 \mathrm{~kg} / \mathrm{m}^{2}$, and most patients of this series who died were having low BMI. This is in contrast to mortality due to cardiovascular diseases, which is generally higher in obese patients and patients with BMI more than $30 \mathrm{~kg} / \mathrm{m}^{2}$, this "BMI Paradox" has been detected in other chronic diseases like heart failure $(\mathrm{HR})$ where death rate is low in case of higher $\mathrm{BMI}^{15}$. It has been seen also that low BMI was commonly prevalent with advanced COPD, which cause skeletal 
muscle loss due to lack of fat and may contribute in severity of the disease causing deterioration in clinical condition of patients ${ }^{40}$.

The prolonged use of Fluticasone proved to be helpful to reduce the decline in patients' health condition, though it might cause a slight increase in hemoglobin glycation in case of high doses more than $2 \mathrm{mg} / \mathrm{day}^{8}$. On the other hand, multiple studies were conducted on other Inhaled Corticosteroids (ICS) and the results were controversial some of them showed that the prolong use of ICS caused a minor detectable change in blood glucose level and others failed to do $\mathrm{so}^{9}$. However, majority of studies found that the disturbances were not clinically significant to alter patient condition and requires medical attention or to stop the treatment ${ }^{10-11}$.

The data available about mortality of COPD is limited or lacks in term of details due to lack of studies. The recent studies showed that morbidity due to COPD increased with age, chronic complications like Diabetes Miletus (DM), Hypertension (HTN), and much more frequent in male than female ${ }^{12,13,33}$.

\section{CONCLUSION}

Chronic diseases such as DM can increase the risk for onset of other co-morbid conditions like COPD and can be considered as a factor that accelerate decline in lung function. BMI of diabetic patients with COPD had an inversely proportional relationship with COPD, so the lower the BMI the higher the risk of mortality.

\section{RECOMMENDATIONS}

Further studies based on clinical and experimental models at molecular level should be conducted to establish this correlation between COPD and DM.

\section{CONFLICT OF INTEREST}

There is no any conflict of interest.

\section{REFERENCES}

1. Wild S, Roglic G, Green, A, Sicree, R, King H. Global prevalence of diabetes. Estimates for the year 2000 and projections for 2030. Diabetes Care, 2004; 27(5):1047-53.

2. British Lung Foundation. Living with COPD Booklet BK2. British Lung Foundation, 73-75 Goswell Road, London EC1V 7ER. 2014.

3. Vos T, Barber RM, Bell B, et al (Global burden of disease study 2013 collaborators). Global, regional, and national incidence, prevalence, and years lived with disability for 301 acute and chronic diseases and injuries in 188 countries, 1990-2013: a systematic analysis for the Global Burden of Disease Study 2013. Lancet.2015;386 (9995):743-800.

4. Vos T, Flaxman AD, Naghavi M, et al. Years lived with disability (YLDs) for 1160 sequelae of 289 diseases and injuries 1990 - 2010: a systematic analysis for the Global Burden of Disease Study. Lancet 2012; 380(9859):2163-96.

5. Brown JP, Martinez $\mathrm{CH}$. Chronic obstructive pulmonary disease comorbidities. Curr Opin Pulm Med. 2016 Mar;22(2):113-8.

6. López-Campos JL, Tan W, Soriano JB. Global burden of COPD. Respirology 2016 Jan;21(1):1423.

7. Kian-Chung Ong. Chronic Obstructive Pulmonary Disease - Current Concepts and Practice. 2012. InTech, Rijeka, Croatia - EUROPEAN UNION.

8. Burge PS, Calverley PM, Jones PW, et al. Randomised, double blind, placebo controlled study of fluticasone propionate in patients with moderate to severe chronic obstructive pulmonary disease: the ISOLDE trial. BMJ 2000;320 (7245):1297-303.

9. Egbuonu F, Antonio FA, Edavalath M. Effect of Inhaled Corticosteroids on Glycemic Status. Open Respir Med J. 2014; 8: 101-105.

10. Slatore CG, Bryson CL, Au DH. The association of inhaled corticosteroid use with serum glucose concentration in a large cohort. Am J Med., 2009;122(5):472-8.

11. Barbara $P$ Yawn, Yunfeng Li, HaijunTian, et al. Inhaled corticosteroid use in patients with chronic obstructive pulmonary disease and the risk of pneumonia: a retrospective claims data analysis. Int J Chron Obstruct Pulmon Dis. 2013; 8: 295304.

12. National Heart, Lung, and Blood Institute. Morbidity and mortality: chartbook on cardiovascular, lung, and blood Diseases. Bethesda, MD: U.S. Department of Health and Human Services, Public Health Service, National Institutes of Health; 1998.

13. Mannino DM, Thorn D, Swensen A, Holguin F. Prevalence and outcomes of diabetes, hypertension and cardiovascular disease in COPD. Eur Respir J 2008 32(4):962-9.

14. Casqueiro J, Casqueiro J, Alves C. Infections in patients with diabetes mellitus: A review of pathogenesis. Indian J Endocrinol Metab.2012;16 (Suppl 1): S27-36. 
15. Gudmundsson G, Gislason T, Lindberg E, et al. Mortality in COPD patients discharged from hospital: the role of treatment and co-morbidity. Respir Res,2006;7(1);109-16.

16. Makarevich, AE, Valevich, VE, Pochtavtsev AU. Evaluation of pulmonary hypertension in COPD patients with diabetes. Adv Med Sci. 2007; 52; 265-72

17. Parappil A, Depczynski B, Collett P, Marks GB. Effect of co-morbid diabetes on length of stay and risk of death in patients admitted with acute exacerbations of COPD. Respirology. 2010;15(6):918-22.

18. Rogliani $P$, Lucà $G$ and Lauro $D$. Chronic obstructive pulmonary disease and diabetes.COPD Research and Practice: 2015,1:3.

19. Weynand B, Jonckheere A, Frans A, Rahier J. Diabetes mellitus induces a thickening of the pulmonary basal lamina. Respiration. 1999;66 (1);14-9.

20. Mirrakhimov AE: Chronic obstructive pulmonary disease and glucose metabolism: a bitter sweet symphony. Cardiovascular Diabetology 2012; 11:132.

21. Baker EH, Bell D. Blood glucose: of emerging importance in COPD exacerbations, Thorax. 2009;64(10):830-32.

22. Gläser $S$, Krüger $S$, Merkel $M$, Bramlage $P$, Herth FJF. Chronic obstructive pulmonary disease and diabetes mellitus: a systematic review of the literature. Respiration 2015;89(3):253-64.

23. Bose P, Bathri R, Kumar L, Vijayan VK, Maudar KK. Role of oxidative stress \& transient receptor potential in chronic obstructive pulmonary disease. Indian J Med Res. 2015;142(3):245-260.

24. Torres A, Blasi F, Dartois N, Akova M. Which individuals are at increased risk of pneumococcal disease and why? Impact of COPD, asthma, smoking, diabetes, and/or chronic heart disease on community-acquired pneumonia and invasive pneumococcal disease. Thorax. 2015;70(10):984-9.

25. Gill SK, Hui K, Farne H, et al. Increased airway glucose increases airway bacterial load in hyperglycaemia. Sci Rep 2016 8:6:27636.

26. Hunt WR, Zughaier SM, Guentert DE, et al. Hyperglycemia impedes lung bacterial clearance in a murine model of cystic fibrosis-related diabetes. Am J Physiol Lung Cell Mol Physiol. 2014; 306(1):L43-49.

27. Kim HJ, Lee JY, Jung HS, et al. The impact of insulin sensitisers on lung function in patients with chronic obstructive pulmonary disease and diabetes. The Int J Tuberc Lung Dis. 2010;14 (3):362-67.

28. Kapoor D, Kumar P, Ranjan A, et al. Assessment of pulmonary function in patients with type 2 diabetes mellitus: a case-control study. Int $J$ Res Med Sci. 2015; 3(1): 207-13.

29. Ramirez LC, Dal Nogare A, Hsia C, et al. Relationship between diabetes control and pulmonary function in insulin-dependent diabetes mellitus. Am J Med 1991; 91:371-76.

30. McKeever TM, Weston PJ, Hubbard R, Fogarty A: Lung function and glucose metabolism: an analysis of data from the Third National Health and Nutrition Examination Survey. Am J Epidemiol, 2005; 161(6):546-56.

31. Malathy R, Narmadha MP, Ramesh S, Alvin JM, Dinesh BN. Effect of a diabetes counseling programme on knowledge, attitude and practice among diabetic patients in Erode district of South India. J Young Pharm. 2011;3(1):65-72.

32. Archer JR, Baker EH. Diabetes and metabolic dysfunction in COPD. COPD uptodate. Respiratory Medicine. 2009; 5: 67-74.

33. Mahishale V, Mahishale A, Patil B, Sindhuri A, Eti A. Screening for diabetes mellitus in patients with chronic obstructive pulmonary disease in tertiary care hospital in India. Niger Med J. 2015; 56(2): 122-25.

34. Kraft R, Herndon DN, Mlcak RP, et al. Bacterial respiratory tract infections are promoted by systemic hyperglycemia after severe burn injury in pediatric patients.Burns. 2014;40(3):428-35

35. Colca JR. The TZD insulin sensitizer clue provides a new route into diabetes drug discovery. Expert Opin Drug Discov. 2015;10(12):1259-70.

36. Lange $P$, Celli $B$, Agustí $A$, et al. Lung-Function Trajectories Leading to Chronic Obstructive Pulmonary Disease. N Engl J Med. 2015;373 (2):111-22.

37. Klekotka RB, Mizgała E, Król W. The etiology of lower respiratory tract infections in people with diabetes. Pneumonol Alergol Pol. 2015;83(5):401-8.

38. Skowroński M, Zozulińska-Ziółkiewicz D, BarinowWojewódzki A. Tuberculosis and diabetes mellitus - an underappreciated association. Arch Med Sci. 2014;10(5):1019-27.

39. Khafaie MA, Salvi SS, Ojha A, et al. Systemic Inflammation (C-Reactive Protein) in Type 2 Diabetic Patients Is Associated With Ambient Air 
Pollution in Pune City, India. Diabetes Care 2013; 36(3): 625-30.

40. Cho E. Targeting Phosphodiesterase 4 to Block the Link between Acute Exacerbation of Chronic Obstructive Pulmonary Disease and the Metabolic
Complications. J Biosci Med. 2015;3:62-7.

41. Hitchman SC, Fong GT. Gender empowerment and female-to-male smoking prevalence ratios. Bulletin of the World Health Organization 2011;89:195-202.

AUTHOR AFFILIATION:

Dr. Ahmad N. Bitar (Correspondence Author)

Faculty of Pharmacy

University of Sindh, Jamshoro, Sindh-Pakistan.

Email: ahmadnoars@yahoo.com

Dr. Muhammad Ali Ghoto

Faculty of Pharmacy

University of Sindh, Jamshoro, Sindh-Pakistan.

Prof. Dr. Abdullah Dayo

Faculty of Pharmacy

University of Sindh, Jamshoro, Sindh-Pakistan.

Dr. Mudassar Iqbal Arain

Faculty of Pharmacy

University of Sindh, Jamshoro, Sindh-Pakistan.

Rabia Parveen

Faculty of Pharmacy

University of Sindh, Jamshoro, Sindh-Pakistan. 